\title{
In-vitro analysis of potential antibacterial activity of three medicinal plants
}

\author{
Vandana Gupta $^{1 *}$, Rakesh Kumar², Deepika Chaudhary ${ }^{2}$, Nirmal Yadav ${ }^{1}$ \\ ${ }^{1}$ Textile and Apparel Designing Department, CCS Haryana Agricultural University, Hisar-125004 (Haryana), INDIA \\ ${ }^{2}$ Department of Microbiology, CCS Haryana Agricultural University, Hisar-125004 (Haryana), INDIA \\ "Corresponding author. E-mail: vandana.g3129@gmail.com
}

Received: September 18, 2015; Revised received: May 29, 2016; Accepted: August 07, 2016

\begin{abstract}
The present study was aimed to examine and compare the antibacterial activity of hot methanolic extract of medicinal plants viz. Portulaca oleracea (purslane), Syzygium cumini (L.) (jamun), Psidium guajava (L.) (guava). Antibacterial activity was carried by using agar well diffusion method, against Gram-positive bacteria (Staphylococcus aureus and Bacillus subtilis) and Gram-negative bacteria (Escherichia coli). Results indicated that all the three plant extracts possess antibacterial property against Gram-positive bacteria and no activity was found against Gram-negative bacteria. Moderate zone of inhibition against Staphylococcus aureus and Bacillus subtilis was exhibited by S. cumini (L.) $(11 \mathrm{~mm}$ and $12 \mathrm{~mm})$ and $P$. guajava (L.) $(10 \mathrm{~mm}$ and $11 \mathrm{~mm})$ and weak zone of inhibition was exhibited by $P$. oleracea $(5 \mathrm{~mm}$ and $6 \mathrm{~mm})$. In conclusion, $S$. cumini (L.) and $P$. guajava (L.) possess better capabilities of being a good candidate in search for natural antibacterial agent against infections and diseases causing Gram-positive bacteria as compared to $P$. oleracea.
\end{abstract}

Keywords: Agar well diffusion method, Antibacterial activity, Gram-negative bacteria, Gram-positive, Medicinal plants

\section{INTRODUCTION}

In recent years, there have been renaissance of interest in natural or herbal remedies worldwide; partly because of the realization that modern medicine is not capable of proving a "cure- all" solution against human diseases as well as the presence of side effects is almost unavoidable (Hostettmann et al., 1995 and Handa, 2014). Medicinal plants and derived medicine are widely used in traditional cultures all over the world and they are becoming increasingly popular in modern society as natural alternatives to synthetic chemicals (Dixit et al., 2013). Medicinal plants represent a rich source from which antimicrobial agents may be obtained due to the presence of active compounds such as tannins, flavonoids, terpenoids, saponins (Mujeeb et al., 2014). These active compounds can inhibit the growth of microbes in many ways such as by inhibiting protein synthesis, interfering with nucleic acid synthesis, breaking the peptide bonds, acting as chelating agents, inhibiting metabolic pathways, interfering with cell wall synthesis or by preventing utilization of available nutrients by the microorganisms (Sumitra and Kaneria, 2011). Now-a-days, herbs are selected as antibacterial sources due to the development of drug resistance in human pathogens against commonly used antibiotics (Dixit et al., 2013). Unlike modern drugs that invariably comprise of a single active species, the plant extract contain multiple active compounds which render them with medicinal characteristics (Donehower and Rowinsky, 1993). In 2009
WHO called antibiotic resistance one of the three greatest threats to human health, and in 2011 the focus of World Health Day was 'Combating Antibiotic Resistance' (World Health Organisation 2011). Numerous studies have been conducted with the extracts of various plants and revealed the health benefits of medicinal plants such as Portulaca oleracea, Syzygium cumini (L.), Psidium guajava (L.). But no comparative analysis of their antibacterial properties is being made till date. $P$. oleracea belongs to Potulacaceae family and is also known as Purslane. Leaves and stem of $P$. oleracea is reported to be used as antidiarrhoeal, antihelminthic, antiphlogistic and bactericide in bacillary dysentery, hemorrhoids, enterorrhagia, antidiabetic (Bakkiyaraj and Pandiyaraj, 2011). Whereas, leaves of S. cumini (L.) (jamun) belonging to Myrtaceae family, used in diabetes, antiallergic, antioxidant, antiviral, antibacterial, anti inflammation and helps in preventing DNA damage. (Chaudhary and Mukhopadhyay, 2012). Leaves of P. guajava (L.) (guava) belonging to Myrtaceae family, are used in diahrrhea, dysentery, gastroenteritis, anti cough, ulcers, bowels, cholera, hypoglycaemic, anti-infammatory, analgesic, antipyretic (Dey et al., 2010). The present study was aimed to determine the antibacterial potential of three medicinal plants viz. P. oleracea, S. cumini (L.), P. guajava (L.) along with their comparative analysis. The selection was guided by lack of information in literature on comparative study of antibacterial activity of hot methanolic extract of the selected plants. 


\section{MATERIALS AND METHODS}

Collection of plant material: Mature leaves and stem of $P$. oleracea, leaves of $S$. cumini (L.) and P. guajava (L.) were collected from Haryana Agricultural University, Hisar, Haryana during the month of April 2014. The collected plant material was thoroughly washed under tap water, rinsed in distilled water and shade dried.

Preparation of methanol extract: The shade dried plant material was grounded into powder. About 40 gm powder was extracted with $250 \mathrm{ml}$ of methanol at $55-60{ }^{\circ} \mathrm{C}$ for 4 hours. The extracts obtained were filtered, concentrated after dryness in rota vapor. The dried extracts were stored in air tight containers at $4{ }^{0} \mathrm{C}$ for further study. (Choudhary et al., 2012)

Test organisms: The pure cultures of common human pathogenic Gram-positive bacteria (Staphylococcus aureus and Bacillus subtilis) and Gram negative bacteria (Escherichia coli) were obtained from the Department of Veterinary Microbiology, Lala Lajpat Rai University of Veterinary and Animal Sciences, Hisar and sub-cultured in nutrient agar plates and slants. Three to five well-isolated colonies of micro-organism were aseptically transferred into the tube containing $5 \mathrm{ml}$ of Brain Heart Infusion Broth. The inoculated broth tubes were incubated at $37^{0} \mathrm{C}$ for 24 hours. The growth was observed in the form of turbidity and the tubes were stored at $4^{0} \mathrm{C}$ for further experimental work.

Screening of antibacterial activity: The modified agar well diffusion method of Dey et al., (2010) was employed to study the antibacterial activity of the plant extracts. The Nutrient agar medium (28 g nutrient agar in $1000 \mathrm{ml}$ distilled water) was autoclaved at $15 \mathrm{lbs}$ pressure $\left(121^{\circ} \mathrm{C}\right)$ for 15 minutes. After autoclaving, the media was poured into sterilized petri plates with a uniform thickness of approximately $4 \mathrm{~mm}$. The agar plates were allowed to solidify at ambient temperature and were used after 24 hours. Three uniform wells were prepared with the help of sterile cork borer of 5 $\mathrm{mm}$ diameter in agar plates. The entire agar surface was then inoculated by sterile cotton swab dipped in bacterial culture and left for 3 to 4 minutes. Different hot methanolic plant extracts were added to the grooves and one control (methanol) of each was added to groove on separate agar plate. The plates were incubated for 24 hours at $37^{0} \mathrm{C}$. Plates were examined and zone of inhibition of the bacteria growth was measured in mm by using diameter measurement scale. All the assays were performed in triplicate and expressed as average values. Antibacterial activity of plant extracts and control was interpreted as no activity $(-\mathrm{mm})$, weak $(<6 \mathrm{~mm})$, moderate $(7-$ $12 \mathrm{~mm})$ and strong activity $(>12 \mathrm{~mm})$.

\section{RESULTS AND DISCUSSION}

The main objective of this study was to screen antibacterial activity of three medicinal plants and compare them to identify the potential antibacterial plant extract for the therapeutic use. Hot methanolic extracts of the selected parts of the plants were prepared by soxhlet extraction process. Agar well diffusion method was employed to test the antibacterial efficiency of all the three plant extracts. The bacterial resistance was tested against two Gram-positive bacteria $(S$. aureus and $B$. subtilis) and one Gram-negative bacteria (E. coli). The results of the present study revealed that the three hot methanolic plant extracts under study posses antibacterial activity against Gram-positive bacteria $(S$. aureus and $B$. subtilis), which are very much in conformation with the results of the studies conducted by Mohamed et al., 2013. Bakkiyaraj and Pandiyaraj 2011, and Egga et al., 2014. All hot methanolic plant extracts did not display any antibacterial activity against Escherichia coli as presented in table 1. Zero antibacterial activity was exhibited by control (methanol) against tested bacteria under study. The resistance of the Gramnegative bacteria to several plant extracts was previously highlighted by Biswas et al., 2003 and suggested that such activity could be attributed to the cell wall structure of E. coli, as it have an effective permeability barrier, comprised of a thin lipopolysaccharide exterior membrane, which restrict the penetration of the extruding plant extract. Gram positive bacteria have a meshlike peptidoglycan layer which is more accessible to permeation by the extracts. Among the tested plant extracts, moderate zone of inhibition against $S$. aureus was exhibited by $S$. cumini (L.) $(11 \mathrm{~mm})$ and $P$. guajava (L.) $(10 \mathrm{~mm})$ and weak zone of inhibition against $S$. aureus was exhibited by $P$. oleracea $(5 \mathrm{~mm})$. In case of $B$. subtilis moderate zone of inhibition was exhibited by $S$. cumini (L.) $(12 \mathrm{~mm})$ and $P$. guajava(L.) $(11 \mathrm{~mm})$ and weak zone of inhibition was exhibited by $P$. oleracea $(6 \mathrm{~mm})$ as shown in figure 1 . Effective antibacterial activity of leaf extract of $S$. cumini (L.) especially against Gram-positive bacteria ( $S$. aureus) has been reported by Shafi et al., 2002 and Shyamala and Vasantha, 2010, rendered the antibacterial activity to the presence of phenol and tannin constituents in the leaf extract in their study. Goncalves et al., 2008, Sanches et al., 2005, Vieira et al., 2001 reported high activity of guava leaves extract and essential oil against

Table 1: Antibacterial efficacy of hot methanolic leaves extract of selected plants against bacteria.

\begin{tabular}{cccc}
\hline \multirow{2}{*}{ Plants } & \multicolumn{3}{c}{ Zone of inhibition $(\mathbf{m m})$} \\
\cline { 2 - 4 } & S. aureus & B. subtilis & E. coli \\
\hline $\begin{array}{c}\text { P. oleracea } \\
\text { S. cumini(L.) }\end{array}$ & $5 \mathrm{~mm}$ & $6 \mathrm{~mm}$ & - \\
$\begin{array}{c}\text { P. guajava } \\
\text { (L.) }\end{array}$ & $11 \mathrm{~mm}$ & $12 \mathrm{~mm}$ & - \\
$\begin{array}{c}\text { Control } \\
\text { (methanol) }\end{array}$ & - & $11 \mathrm{~mm}$ & - \\
\hline
\end{tabular}

Bacteria activity: - no activity; $<6 \mathrm{~mm}$ : weak; 7-12: Moderate; $>12 \mathrm{~mm}$ : Strong 

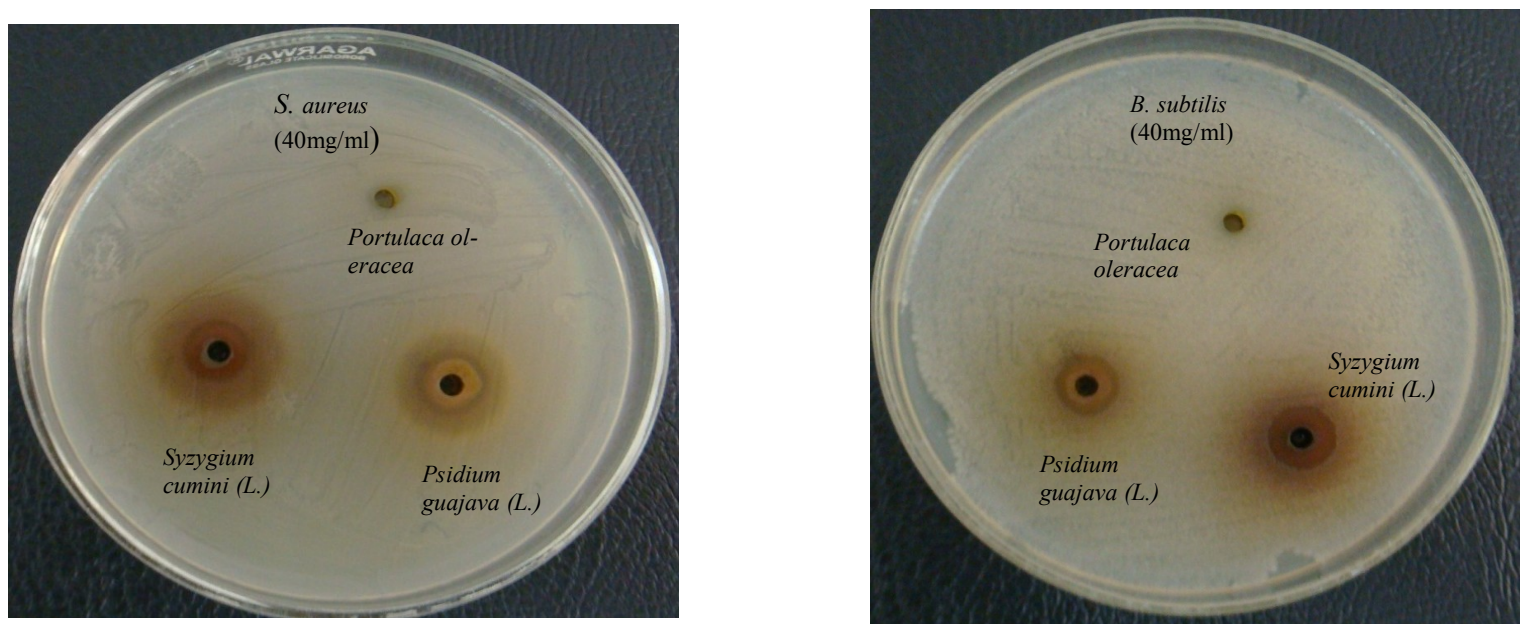

Fig 1. Zone of inhibition of plants under study against Gram-positive bacteria.

S. aureus, which could be attributed to the presence of active compounds such as tannin, flavonoids, eugenol, mallic acid present in the leaves (Ncube et al., 2008). Although Methanolic extract of $P$. oleracea have been reported to possess good antibacterial property against two Gram-positive bacteria ( $S$. aureus and B. subtilis) and such activity was rendered to the presence of chemical compounds of this plant (Bakkiyraj and Pandiyaraj, 2011). Whereas in the present study the antibacterial activity of hot methanolic extract of $P$. oleracea was weak as compared to $S$. cumini $(L$.) and $P$. guajava (L.). This might be due to the difference in number and type of chemical compounds present in the extract, which are responsible for antibacterial property. The results suggest that among the three plants screened hot methanolic extract of S. cumini (L.) and $P$. guajava (L.) belonging to the family Myrtaceae exhibited almost similar antibacterial activity and can be used as potential antibacterial agent against Grampositive bacteria.

\section{Conclusion}

The present work demonstrates the antibacterial potential of hot methanolic extracts of $P$. oleracea, $S$. cumini (L.) and P. guajava (L.). The observed inhibition of Gram-positive bacteria ( $S$. aureus and B. subtilis) suggests that plants under study possess compounds containing antibacterial properties that can effectively suppress the growth when extracted using methanol as solvent. On the basis of the present finding, it can be concluded that S. cumini (L.) and P. guajava (L.) possess better capabilities of being a good candidate in search for natural antibacterial agent against infections and diseases causing Gram-positive bacteria as compared to $P$. oleracea. Also, detailed investigation is required for the quantitative and qualitative analysis of chemical compounds also known as phytochemicals present in the plants under study, which are responsible for their antibacterial activity.

\section{REFERENCES}

Bakkiyaraj, S, and Pandiyaraj, S. (2011). Evaluation of Potential Antimicrobial Activity of Some Medicinal Plants against Common Food-Borne Pathogenic Microorganism. International Journal of Pharma and Bio Sciences. 2(2):B484-491

Biswas, B., Rogers, K., McLaughlin, F., Daniels, D., and Yadav, A.(2013). Antimicrobial activities of leaf extracts of guava (Psidium guajava L.) on two GramNegative and Two Gram-Positive Bacteria. International Journal of Microbiology.2013:1-7

Chaudhary, B. and Mukhopadhyay, K.(2012). Syzygium cumini (L.) Skeels: A Potential Source of Nutraceuticals. International Journal of Pharmacy and Biological Sciences. 2(1): 46-53.

Choudhary, S., Sharan, L. and Sinha, M.P.(2012). Phytochemical and Antimicrobial Screening of psidium Guajava L. Leaf Extracts against Clinically Important Gastrointestinal Pathogens, J.Nat. Prod. Plant Resour. 2 (4):524-529.

Dey, S.K., Banerjee, D., Chattapadhyay, S. and Karmakar, K.B. (2010). Antimicrobial activities of some medicinal plants of West Bengal. International journal of Pharma and Bio Sciences. 1(3):1-10.

Dixit, P., Tripathi, S., Verma, K.N. 2013. A Brief Study On Marigold (Targets Species): A Review. International Research Jaurnal Of Pharmacy. 4(1)43-48.

Donehower, R.C. and Rowinsky, E.R. (1993). Cancer Treat Rev 1993;19C:63 Egga E.S., Adeyanju O., Agyens O.E. 2014. Preliminary Phytochemical, Antibacterial and Proximate Analysis of Tender Leaves of Psidium guajava L. in Jos, Plateau State, Nigeria. Asian Review of Environmental and Earth Sciences. 1(2):35-38

Goncalves, F.A., Andrade, M., Bezerra, J.N.S et al. (2008). Antibacterial activity of guava,

Psidium guajava Linnaeus, leaf extracts on diarrhea-causing enteric bacteria isolated from seabob shrimp, Xiphopenaeus Kroyeri (Heller)," Revista do Instituto de Medicina Tropical de Sao Paulo. 50(1):11-15

Handa, D. and Sharma, K. (2014). A Review: Plant Extracts a New Source of Antimicrobial

Potential. Research Journal of Pharmaceutical, Biological and Chemical Sciences. 5(3): 597-628 
Hostettmann, K., Marston, A., Maillard, M., Hamburger, M. (1995). Phytochemistry of plants used in traditional medicine. Claredon Press, Oxford.

Mohamed, A.A., Ali S.L.,EL-Baz, F.K. 2013. Antioxidant and Antibacterial Activities of Crude

Extracts and Essential oils of Syzygium cumini Leaves. PLoS One. 8(4):e60269.doi:10.1371/journal.pone.0060269

Mujeeb, F., Bajpai, P., and Pathak, N.(2014). Phytochemcial Evaluation, Antibacterial Activity, and Determination of Bioactive Components from leabes of Aegle Marmelos. BioMed Research International.2014:1-11

Ncube, N.S., Afolayan, A.J., and Okoh, A.I. (2008). Assessment of antimicrobial properties of natural compounds of plant origin: current methods and future trends. African Journal of Biotechnology. 7(12): 1797-1806

Sanches, N.R., Cortez, D.A.G., Schiavini, M.S., Nakamura, C.V., and Filho, B.P.D.(2005). An evaluation of antibacterial activities of Psidium guajava (L.)." Brazilian Archives of Biology and Technology. 48(3):429-436

Shafi, P.M., Rosamma, M.K., Jamil, K., Reddy, P.S. (2002).Antibacterial activity of Syzygium cumini and Syzygium travancoricum leaf essential oils. Fitoterapia 73 (5): 414-416. doi: 10.1016/s0367-326x (02)00131-4

Shyamala, S.G., Vasantha, K. (2010). Phytochemical screening and antibacterial activity of Syzygium cumini (1.) (Myrtaceae) leaves extracts. Int J Pharm Technol Res. 2 (2):1569-1573

Sumitra C. and Kaneria M. 2011. Indian nutraceutical plant leaves as potential source of natural antimicrobial agents. Retrieved from http://www.formatex.info/ microbiology3/book/1251-1259.pdf

Vieira, R.H.S.D.F., Rodrigues, D.D.P., Goncaves, F.A., Menezes, F.G.R., Aragao, J.S. and Sousa, O.V. (2001). Microbial effect of medicinal plant extracts to acnedeveloping organisms. The American Journal of Chinese Medicine. 33(2):197-204.

World Health Organization. Antimicrobial resistance: no action today, no cure tomorrow. http://www.who.int/ world-health-day/2011/en/index.html (19 April 2011, date last accessed). 